\title{
SE EDUCAÇÃO É A RESPOSTA. QUAL ERA A PERGUNTA? *
}

\author{
CARLOS ALBERTO MOLINARO**
}

Dedicado aos colegas, docentes e discentes, da Faculdade de Direito da PUCRS

\begin{abstract}
RESUMO: A proposta principal deste paper está em que uma educação em direitos humanos conduz a uma cultura de direitos humanos e, conseqüentemente, a uma sociedade civil estável. Educação em direitos humanos está se tornando um ingrediente essencial para todas as sociedades no mundo de modo a encorajar o respeito e a tolerância a estes ao nosso redor, e a construir cidadãos comprometidos com o futuro dos direitos humanos e com a proteção ativa da dignidade da pessoa humana. Educação em direitos humanos pressente claramente não uma educação em direitos humanos como um fim em si mesmo, mas como um processo de apoderamento, um meio de transformação, e um mecanismo para chamar a atenção para os abusos. Assim, uma efetiva educação em direitos humanos tem dois objetivos essenciais: aprendendo sobre direitos humanos e aprendendo para direitos humanos. PALAVRAS-CHAVE: Direitos Humanos, Educação, Empoderamento.
\end{abstract}

ABSTRACT: The main proposal of this paper is that human rights education leads to a culture of human rights and hence a stable civil society. Human rights education is becoming an essential ingredient to all societies in the world in order to encourage respect and tolerance to those around us, and form citizens committed with the future of the human rights and with the active protection of the human person's dignity. Human rights education clearly envisions human rights education not as an end in itself, but as an empowerment process, a means of transformation and a mechanism to address abuses. Thus, effective human rights education has two essential objectives: learning about human rights and learning for human rights.

KEYWORDS: Human Rights, Education, Empowerment.

SUMÁRIO: Considerações introdutórias. 1. Modo de expressar o agir do humano. 2. A educação está no centro de nosso futuro: lugar apropriado para um aprendizado e crítica dos direitos humanos. 3. Uma educação em direitos humanos, e em direitos fundamentais, implica uma fundamentação filosófica e uma crítica destes mesmos direitos. 4. O que queremos dizer quando falamos de fundamentação filosófica e crítica dos direitos humanos e dos direitos fundamentais. Considerações finais. Referências Bibliográficas.

* Tomando emprestado e parafraseando o título de um livro de G. Wagensberg Si la naturaleza es la respuesta, ¿Cuál era la pregunta? y otros quinientos pensamientos sobre la incertidumbre. Barcelona: Tusquets Editores, 2001.

** Doutor em Direito, summa cum laude, com "menção européia" pelo Departamento de Direito Público da Universidade "Pablo de Olavide" de Sevilha, Espanha. Mestre e Especialista em Direito pela Pontifícia Universidade Católica do Rio Grande do Sul. Professor na Graduação e Pós-Graduação (Mestrado e Doutorado) da FADIR-PUCRS e no Doutorado em Direitos Humanos da UPO-ES. (carlos.molinaro@pucrs.br). 
“A educação está no centro de nosso futuro. O futuro é estruturado pela educação que é dispensada no presente, aqui e agora... Aprender a conhecer significa, antes de tudo, a aprendizagem dos métodos que nos ajudam a distinguir o que é real do que é ilusório, e a ter assim um acesso inteligente aos saberes de nossa época. Neste contexto o espírito científico, uma das maiores aquisições da aventura humana, é indispensável. [...] No entanto, ensino científico não quer dizer de modo algum aumento desmedido do ensino de matérias científicas e construção de um mundo interior baseado na abstração e na formalização. Tal excesso, infelizmente comum, só poderia conduzir àquilo que é oposto do espírito cientifico: as respostas prontas de outrora seriam substituidas por outras respostas prontas (desta vez com uma espécie de brilho "cientifico") e, no fim de contas, um dogmatismo seria substituído por outro."

Bassarab Nicolescu***

\section{CONSIDERAÇÕES INTRODUTÓRIAS}

Parafraseando Zaratustra, ${ }^{1}$, podemos perguntar até que ponto se amplia se é que se amplia - a analogia entre a distinção moral e a distinção gnosiológica? A "apreensão" intelectual sutil da verdade e do falso está superada, já que fica inaugurado um novo estado do humano mais além do bem e do mal. O que Nietzsche - por vezes mal compreendido - acentua, é que "renaturalizar o homem" não significa devolver-lhe a um estado natural prévio à civilização, mas consagrar um novo pacto entre o homem e a natureza graças a uma liberalização desta, liberalização da fragmentação ocorrida na sua dimensão metonímica: a cultura. Não mais a dicotomia do verdadeiro/aparente, ou da verdade e do falso, agora se abre um caminho novo "mais além da verdade e da aparência, mais além da verdade e da falsidade". Um caminho não cindido, onde o particípio revela uma substância única (natureza/cultura), nem falsa nem verdadeira, pois como dizem os poetas, não há um rosto atrás das máscaras. O rosto é a máscara.

Revelar uma postura epistêmica ${ }^{2}$ despida de crenças e tendências culturais acumuladas no desenvolver da vida social e pedagogicamente estruturada não é tarefa fácil, remanescem preconceitos e pré-juízos fortemente ancorados na "máscara" que se revela como o duplo do próprio rosto. Contudo, o caminho tortuoso - que os gregos tão bem denominavam de $\sigma \kappa o \lambda \iota \omega ́ \varsigma$ (scolios, escolio) ${ }^{3}$ - do desnudar-se

\footnotetext{
*** Manifesto da Transdisciplinaridade. S. Paulo: Triom, 1999, p.132.

${ }^{1}$ Nietzche F., Así habló Zaratustra. Un libro para todos y para nadie. Madrid: Alianza, 1972.

${ }^{2}$ No sentido de episteme, como em Foucault, um paradigma estrutural múltiplo de saberes intermediados e não concludentes, um aberto desde três dimensões, uma delas dedicada às ciências matemáticas e físicas onde a ordem é sempre um encadeamento dedutivo de posições evidentes e verificáveis; outra, as ciências da vida, da produção e distribuição das riquezas, da linguagem; estas se desenvolvem desde elementos descontínuos, mas análogos, cujas relações são causais e de constante ruptura. A terceira dimensão é pertencente ao domínio filosófico, da reflexão e da ponderação (do "Mesmo" foucauliano). Destas dimensões são excluídas as ciências humanas, pois é no domínio delas numa relação apotética/paratética que elas (as ciências humanas) encontram o seu lugar onde se põem em relação com outros saberes (Cf. Foucault, M., As palavras e as coisas. Trad. De A. R. Rosa. Lisboa: Martins Fontes/Portugália Ed., s/d., possivelmente de 1967, p. 450-451 (ed. francesa Galimard, 1966).

${ }^{3}$ Não confundir com homônimo escólio, comentar, interpretar.
} 
das vestes dos metafisismos e tantos outros "-ismos", adquiridos na formação acadêmica tradicional, é necessário se quisermos fazer ciência numa perspectiva culturalista. $\mathrm{O}$ primeiro passo desta jornada está na superação das cosmovisões religiosas, estamentais, tradicionais, para uma estética de mundividência; o segundo movimento está em não entender a realidade como uma função do discurso, sim, justamente o contrário, pois não vale à pena salvar a especificidade do subjetivo a custa de negar toda a objetividade. Revelar uma postura epistêmica é revelar uma equilibrada relação entre subjetividade e objetividade, ou como diz J. Searle, entre fatos e construtos ${ }^{4}$ : pois a realidade é uma construção social, mas o próprio ato de construção se fundamenta no reconhecimento, não por implícito, menos por iniludível, de que tanto o produto, como o instrumento social deste ato, são, por sua vez, reais ${ }^{5}$.

Nos últimos tempos cresce a consciência da necessidade de desenvolver outros modos de relação entre as pessoas, não aqueles que de costume são praticados em nossas sociedades. Estamos habituados a chamar de diálogo ao que, na realidade, é discussão ou debate. Ao proceder deste modo, formamos consensos que tendem a perpetuar o ânimo competitivo e excludente que predomina em nossa cultura, que tem sido associado, com uma freqüência cada vez maior, à violência, à exclusão social e outros meios deformados de convivência. É preciso romper com a dialética negativa do "amo e escravo" para uma dialética afirmativa das condições atributivas desses, isto é, não basta negar essa condição, antes afirmá-la, demonstrá-la, para através do reconhecimento, aí sim, estabelecer bases seguras para a transformação deste status que, em última análise, revela a relação sujeito-objeto, sendo o outro sempre objeto.

A estética e a educação (no sentido paidético) implicam um predicado que introduz o paradigma do aprendendo a apreender ${ }^{6}$ como um dever humano inarredável; vivemos um tempo de grandes inovações tecnológicas que apontam para a necessidade de resignificar as várias dimensões da participação do ser humano no cotidiano, que só pode ser educacional. Mas, como aprender a apreender?

A resposta pode ser encontrada na relação entre a dimensão estética e a dimensão pedagógica do pensar e do agir, a possibilidade singular de desenvolver a passagem do pensamento linear ao pensamento sistêmico e complexo por intermédio do uso de recursos expressivos que nos fornece a razão sensivel $l^{7}$; por isso, devemos valorar uma perspectiva sistêmica construtiva, criadora de sentido e qualidade de consciência que traduza o potencial de transformação da pedagogia social. Devemos trabalhar melhor e acreditar na importância das questões sociais emergentes de nossa conflituosa sociedade e, dado a sua complexidade, interpretar a tarefa educativa como uma intervenção na realidade do momento presente. Isto nos força a pensar,

\footnotetext{
${ }^{4}$ Searle, J., La construcción de la realidad social. Barcelona: Paidós, 1997.

${ }^{5}$ Cf. Candel, M., Prólogo, in, Searle, J., Libertad y neurobiología, Barcelona: Paidós, 2005, p. 12.

${ }^{6}$ Vale dizer, aprendendo com profundidade, inquietar-se intelectualmente, refletir sobre a condição de (im)permanência de todas as coisas no cronotopos em que estamos inseridos.

${ }^{7}$ Por razão sensivel queremos referir a capacidade humana em captar e representar as formas cognitivas da realidade, desde uma proporção que reconheça similitudes e diferenças, diria Aristóteles, a percepção que nós percepcionamos - atualidade do sensivel e do sensitivo (Del Alma, 425b, in, Obras Completas. $2^{\mathrm{a}}$ ed. Madrid: Aguilar, 1967, p. 860)
} 
integrar e resignificar os temas transversais e os valores humanos para a construção de uma nova tomada de posição em relação a estes mesmos temas. Enfim, é de toda importância refletir sobre a representação simbólica da passagem do lamentável para o admirável, sob o ponto de vista da estética e da educação, tudo para permitir a construção de uma nova consciência, através da apercepção ${ }^{8}$ estética, desde uma perspectiva sistêmica, modal $^{9}$ e complexa.

Portanto, nem racionalismos nem empirismos, nem "neos-" de qualquer espécie, nem nominalismos, idealismos ou realismos como postura radical. Fazer ciência exige mais, exige a parcialidade assentada numa "neutralidade possivel"10. A neutralidade responsável, que sabe colher da floresta do pensamento o fruto doce da superação de todas as vaidades intelectuais, inclusive, a de confessar sua absoluta ignorância só superada pelo reconhecimento de que o aprendizado é tarefa de construção constante, proporcional, revelada pela igualdade entre os meios que dispomos e os fins que pretendemos alcançar.

Uma "neutralidade possível" (!) revela o sujeito como agente capaz de linguagem e ação, que reproduz a mudança como um processo criativo e evolutivo. Para essa "neutralidade possível", o sistema coloniza o mundo da vida e é desde este marco que se projeta a ação do sujeito em emancipação. Está como um sujeito é autocrítico podendo abstrair-se da ação estratégica, do poder-manipulação; tudo isso, desde uma razão não-excludente, na qual a interação simbólica se prova a partir da boa fé dos interlocutores, da compreensão e entendimento das atitudes e representações simbólicas dos mesmos, tudo com o objetivo de lograr, finalmente, o consenso. O método para lográ-lo é a "dialógica" e uma "dupla hermenêutica" e, aí, Paulo Freire era insuperável quando dizia: "[...] el diálogo es el encuentro amoroso de los hombres que, mediatizados por el mundo, se "pronuncian”, esto es, lo transforman y, transformándolo, lo humanizan, para la humanización de todos... No hay ni puede haber invasión cultural dialógica; manipulación y dialógica son términos excluyentes"11.

\footnotetext{
${ }^{8} \mathrm{O}$ termo apercepção - apperceptio - foi criado por Leibniz e por ele utilizado no sentido de consciência das próprias percepções, e.g., a percepção da luz ou a do calor que é composta por muitas pequenas percepções. Um ruído que percebemos, mas que não damos à atenção, contudo, ao crescer de volume, torna-se aperceptível. Os animais têm percepções, mas não têm apercepções, porque as apercepções são próprias dos homens, já que suas percepções são acompanhadas pela potência do refletir. A atividade intelectual é, conseqüentemente, uma atividade predominantemente aperceptível, pois além de percebermos como sujeitos perceptivos nos distinguimos da coisa percebida; empregamos essa capacidade em dimensão especialíssima, para definir, com rigor, ampla gama de representações as quais lhes atribuímos valor.

9 Aqui utilizamos o termo modal no seu sentido estatístico e lógico; no primeiro significado, a idéia da variabilidade do valor (a moda estatística); no segundo, como proposição afirmativa ou negativa que estabelece vínculos entre o necessário e desnecessário, o contingente ou incontingente, a possibilidade ou impossibilidade dos termos constituintes.

${ }^{10}$ Todo o analista tem o dever de procurar não dirigir o tratamento que dá a questão investigada segundo sua particular concepção de mundo, ou de seus ideais, sim a de manter-se neutro (o quanto possível) frente às manifestações decorrentes do objeto investigado. Esta neutralidade está diretamente ligada a sua qualidade de agente produtor de conhecimento e está possibilitada pelo desnudamento de seu eu egótico, psicológico. Contudo, atente-se, neutralidade não é indefinição, falta de comprometimento ou insensibilidade, "Neutralidade possível" é aquela que não sacrifica à verdade ou à justiça por considerações particulares A "neutralidade" se afere como se afere o $p h$ dos líquidos, nem ácido, muito menos, básico $(p H \$ 7)$. A proporcionalidade química tem muito a ensinar às ciências sociais.

${ }^{11}$ Freire, P., ¿Extensión o Comunicación? La concientización en el medio rural. México: Siglo XXI, 1979, p. 46.
} 
Uma "neutralidade possível" é a que revela um sujeito portador de uma subjetividade (a supere ou não) que enuncia sua história pessoal em uma rede de sentidos e significados que possui como estrutura de disposição: uma personalidade comprometida com o outro. Contudo, esse comprometimento, personalíssimo, deixa de ser uma instância interna, determinista, relacionada a invariantes conformadas em momentos passados da história individual, para transformar-se em um sistema, que se encontra em uma dimensão procedimental em tensão permanente com as suas produções atuais efetivas e afetivas. Assim o é, pois, a personalidade, ao igual que o sujeito, incorpora uma instância criadora e descobridora de sentidos, os quais são iniludíveis dentro do contexto de ação do sujeito; todavia, esses sentidos não se impõem à ação deste, antes, é ela uma parte do processo gerador que acompanha a ação.

Uma "neutralidade possível" não é uma postura adiáfora ${ }^{12}$ como a entendiam os estóicos, mas, uma atitude justificável que tem sede numa hermenêutica diatópica ${ }^{13}$, um método de revelar o discurso desde uma interpretação não mais morfológica ou diacrônica, antes uma interpretação transversal-argumentativa, onde a trasversalidade dos discursos garante a importância de cada um deles. Todos sabem que os fundamentos mais sólidos para os mal-entendidos havidos nas relações inter-humanas num cronotopos dado, e a distância que temos de superar para pôr a dialogar duas razões antinômicas, mas igualmente importantes. Esta distância não é só fatual (interpretação morfológica) ou temporal (interpretação diacrônica), ela é espacial, vale dizer, nos deparamos com diferentes topoi cujos postulados são radicalmente diversos e respeitáveis, tendo em vista que esses não se desenvolveram desde uma narrativa comum, sim dispondo de diferentes meios de inteligibilidade.

Daí que a hermenêutica diatópica - imprescindível em toda a atividade pedagógica - transita por estas distintas razões justajacentes e por vezes contraditórias entre si (mas também naquelas sobrejacentes ou subjacentes, mas com outro grau de tradução) permitindo um diálogo para a emergência de um texto que seja um elo comum de inteligibilidade (é dia-tópico, pois atravessa os "topoi" para conformar-se), é na tradução que se vai intentar decifrar a textura do contexto, superando as distâncias, levando em consideração, neste percurso, a superação da distância, não do presente em relação ao passado, ou do passado em respeito ao presente, sim a do presente com respeito ao presente, refutando toda a entronação do futuro no presente. Esta "neutralidade possível" é a que pretendemos vestir no curso deste estudo. Uma neutralidade possível está sempre amparada na parcialidade conseqüente, pois como ensina Marvin: [...] No hay por qué considerar el canibalismo, la guerra, el sacrificio humano y la pobreza como logros culturales valiosos para llevar a cabo un estudio objetivo de estos fenómenos. Nada hay de malo en tratar de estudiar ciertas pautas culturales porque se desee cambiarlas. La objetividad cientifica no tiene su origen en la

${ }^{12}$ No sentido de indiferente, isto é, objetos ou coisas que não contribuem nem para a virtude nem para a maldade. No sentido kantiano de ações moralmente indiferentes (Cf. Kant, I., La religión - dans le limites de la simple raison. Trad. J. Gibelin, 10. ${ }^{\text {a }}$ ed. Paris: Librairie Philosophique J. Vrin, 1952, p. 41; obra belíssima que precisa ser relida nestes tempos de fundamentalismos).

${ }^{13}$ No sentido que lhe atribui R. Pannikar in, Cross Cultural Studies: The need for a new science of interpretation, Interculture, v, VII, n. 3-5, Cahier 50, 1975; e Myth, Faith and Hermeneutics. New York: Paulist Press, 1979. 
ausencia de prejuicios -todos somos parciales-, sino en tener cuidado de no permitir que los propios prejuicios influyan en el resultado del proceso de investigación. ${ }^{14}$... E de comunicação (acrescentamos).

\section{MODO DE EXPRESSAR O AGIR DO HUMANO}

O agir humano se manifesta fundamentalmente desde quatro grandes vias comunicativas: o sentir, o saber, o decidir e o fazer. Todo homem e mulher pelo sentir são também influenciados pelos sentimentos exteriores do seu entorno, ao mesmo tempo em que, nos seus interiores, se (con)formam seus próprios sentimentos, emoções e paixões. Ademais, é pelo saber que esse mesmo par, apropria o cotidiano e o especializa desde as dimensões interiores, do imaginário e do conteúdo de sua memória. Sua ação se exterioriza pelo decidir e pelo fazer. Ao decidir, imprescindível à autonomia da vontade e a condição de igualdade, pressuposto de liberdade, que desfrutam. Estes são termos indispensáveis para o vôo da criatividade que encontra concretização no fazer: um fazer que, na origem, é individual e logo se coletiviza, desde as dimensões do estético, do ético e do técnico.

É o mundo sensível que se conecta ao sentir do humano, é através da sensação que os estímulos externos encontram acolhida nos centros nervosos do antropos, e propiciam a adaptação necessária ao mundo. Assim, é a sensação (manifestação do sentir) o modo mais espontâneo da consciência. Contudo, atente-se que a consciência não é só a sensação, pois ela também se manifesta no encontro com o outro e se socializa, emergindo numa consciência plural. Portanto, sentimentos, emoções e paixões (por vezes racionais, na maior parte delas, ou mesmo irracionais) induzem a uma cultura egocêntrica, prenhe de mitos e crenças, mas, também de produtos derivados de uma racionalidade estrita, a priori, que em momentos distintos da história produziu os graves desastres culturais da humanidade (ideologias radicais de qualquer tipo). A conexão se dá pelo saber, ou melhor, se dá pela possibilidade do saber.

O saber é sempre plural, pois é o produto de saberes e de sabores. Recordemos que na origem o étimo é comum, todo saber é sabor (sapor), e sabor, nos ensinam os léxicos, é a sensação que certos corpos ou substâncias exercem sobre os órgãos do paladar. Ademais, paladar é um substantivo que denota toda e qualquer capacidade de apreciar as qualidades e os defeitos dos estímulos que provocaram as sensações. Os saberes como os sabores se singularizam na consciência do sujeito que os interroga ou os confronta. O saber além de plural é complexo, pois ele sempre se apresenta como uma totalidade atributiva mais ou menos coerente, composto de relações interdependentes, mas, por vezes e na maioria delas, subordinadas. Como totalidade, o saber se fraciona em dimensões muito bem definidas no cronotopos investigado: (a) saberes do cotidiano, tradicionais (estáticos, frutos imemoriais, transgeracionais) e adquiridos (dinâmicos, transmitidos, transformados, intergeracionais); (b) saberes especializados, teóricos e práticos, os primeiros, denominados de científicos que podem ser formais ou empíricos, ao lado daqueles alcunhados de metafísicos, como os teológicos e os ontológicos em geral; os segundos, os saberes práticos, ou resultam de técnicas, ou derivam da moral; finalmente (c) os saberes críticos, resultantes das crises do

${ }^{14}$ MARVIN, H., Introducción a la antropología general. Madrid: Alianza editorial, 1984, p. 125 
sujeito cognoscente frente ao objeto cognoscido, eles se utilizam de metalinguagens para romper a tensão entre crítica e crise pela distinção e pela interpretação do objeto interrogado ${ }^{15}$.

Os saberes críticos fazem de seu objeto mil pedaços, visibilizando e invisibilizando a substancialidade fática que lhes remanesce subjacente. Por isso, ao interpretarmos o mundo está colocado fora, não é invento do sujeito. O mundo vai situando-se, sem repouso, entre o corpo que vê e as coisas visíveis, e o que permanece ainda invisível. Entre o lugar do corpo e o lugar das coisas percebe-se uma fratura insuperável. Todavia, a visão não é assunto exclusivo nem do que vê nem tampouco do visível e, todavia, a visão é "ato de ver", e é também "aparição" (Merleau-Ponty), com a educação o mesmo se dá.

De onde provém a ruptura entre o interior e o exterior? - Pergunta o filósofo. "Vejo o mundo", responde. - De acordo. O mundo não é mais do que aquilo que vemos. Mas, será? O fato do aparecer do mundo constitui a entidade deste. Mas, não só nos pasmamos ante o mundo, ademais, encontramo-nos pasmados diante de nosso próprio pasmo, como alguém já afirmou. Aí, criticamos, discernimos. O mistério não é unicamente o mundo, mas, igualmente, a maravilha que experimentamos diante dele. O educar não é o mesmo? Observemos: a besta vive estimulada pelo mundo - não distingue, não separa. O ser humano, ademais, pode viver o mundo sem motivos, mas sempre com a capacidade de questioná-lo. Ao questioná-lo se educa. A interrogação vai mais além da presença mundanal.

Que o mundo possa ficar submetido a questionamentos não significa que não se identifica conosco mesmo, que seu "aparecer" não esgota seu ser. Contudo, daqui não se pode deduzir que ficamos remetidos a outro mundo. A percepção acaba em uma forma de interrogar. O visível encerra em si mesmo o inapresentável. O ser se desborda de sua manifestação. O invisível não é "outro possível”, agora ausente, Ele é - como afirmava Merleau-Ponty ${ }^{16}$, porventura relendo Heidegger - Verbogenheit ${ }^{17}$ fundamental. O visível não é mais que "ruínas" e quebra do invisível. O invisível é invisível do visível, é o "não apresentável", algo assim como um estuário do não-ser ${ }^{18}$. Aí nos encontramos confrontamos com nosso objeto: entre a crítica visivel do saber sobre uma crise invisivel dos saberes, é dizer, nos encontramos num pós-modernismo mundanal onde as situações-limite (na linguagem de Jaspers) se encontram na leitura do mundo como um conjunto de símbolos de outra realidade que jamais poderemos alcançar, pois "somos nós mesmos entrando nas situações-limite [...] Experimentá-las e existir são uma mesma coisa" "19 . Pois, explica Jaspers, os acontecimentos, a ordem objetiva das coisas e as figurações precisam ser decifradas. Assim, toda a filosofia, e com mais razão a filosofia da ciência, consiste em esclarecer a existência possível, não àquela já dada, consiste, pois, em educar o "ver" e o "escolher".

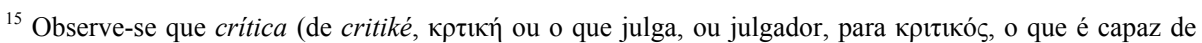

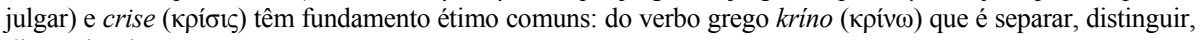
discernir e interpretar.

${ }^{16}$ Le visible et l'invisible. Paris: Gallimard, 1964, p. 32

${ }^{17}$ [O] segredo, vale dizer, o sentido, o significado oculto de algo que se descobre no recolhimento.

${ }_{18}$ Merleau-Ponty, ob. cit., loc. cit.

19 Jaspers, K., Philosophie (1932), trad. Filosofia. Madrid: Revista de Occidente, 1959, p. 79
} 
Como seres humanos, temos de escolher entre saberes e refinar nossa percepção dos sabores. Aí está o trágico de nossos dias. Aí está a dificuldade da crítica. Mesmo, aí se encontra a crise de nossas escolhas. Escolhas fundadas na perspectiva do saber desde três fundamentos bem definidos: (1) um fundamento ontológico, (2) um reflexivo, e (3) um empírico. Em (1), nos encontramos com as idéias e a possibilidade de concretude delas no mundo real (um confronto entre Platão e Aristóteles); em (2), afrontamos a razão moderna, indecisos pelas condições a priori do conhecer abraçamos a inovação, mas persistimos no presuntivo (Schelling ${ }^{20}$ contra Kant); em (3), um fundamento empirista, onde o que pretendemos é um pacto entre crenças e os dados da experiência (Locke dialoga com Hume), já que só o conhecimento sensível nos põe em contato com a realidade.

Com esses instrumentos nos ocupamos do saber. Primeiro, desde uma perspectiva onde só nos interessa a coerência do discurso, relevando em segundo plano o questionamento sobre o seu valor objetivo; segundo, só nos interessamos pelo ato mesmo da aprendizagem (competência para...). Mas, quando o saber compromete (!), nos importamos verdadeiramente com indagar as relações que existem entre as estruturas sociais e os tipos de conhecimentos envolvidos.

$\mathrm{O}$ decidir é sempre um conseqüente. Nas ciências matemáticas, o conseqüente é sempre o segundo termo de uma razão, por isso, ele é também o nome dado aos denominadores de uma proporção. O decidir é sempre proporcional ao produto do sentir e do saber. Revela um sentimento estético de equilíbrio. Essa dimensão de proporção, ou a dieta pitagórica ${ }^{21}$ (em grego $\delta l \alpha ı \tau \alpha$, i.é., justa medida ou moderação), é o que permite, por vezes, a "provisão" 22 da decisão, pois sempre que menor a razão maior a liberdade, ou como nos ensinam as matemáticas: sempre que há um máximo de razão, aí encontramos um mínimo de liberdade (as progressões matemáticas são provas irrefutáveis). Sempre que decidimos nos arriscamos, pois afrontamos o resultado de uma "separação" dos efeitos do saber e do sentir que originaram a nossa ação ${ }^{23}$. Daí, a proporcionalidade de toda decisão relativamente ao fático revela uma racionalidade conseqüente. A racionalidade conseqüente é um estado que acolhe o razoável, pois é própriamente do razoável a probidade, isto é, a retidão na apreensão cognitiva da realidade. Tomamos decisões a partir do razoável, ao partir desta racionalidade conseqüente que acolhe a justa medida (que procede coerentemente).

\footnotetext{
${ }^{20}$ Schelling, F. W. J., Philosophies de l'Université, Paris: Payot, 1979, p. 88: devemos a Schelling, a afirmação que todo o conhecimento deve ser um ultrapassar a forma, uma ars inveniendi que força o original.

${ }^{21}$ Cf. SOTO RIVERA, R., Kairo-teo-ontología en algunos pensadores grecorromanos, in, Konvergencias, Bayamón [Puerto Rico]: Impresos GLAEL, año II - Edición Diciembre 2003/Enero 2004, p. 2

${ }^{22}$ Utilizamos o termo por metonímia como prescrição, ordem, disposição, desde a perspectiva estética do "olhar por..."

${ }^{23}$ Vamos lembrar aqui, que etimologicamente o verbo decidir provém do latim decido, com "i" forte, e significava separar cortando, despedaçar (o parônimo discido, expressa, também, separar cortando), já decido com "i" fraco, expressava cair, sucumbir, morrer; de qualquer modo, a paronímia existente revela que ao decidir fragmentamos o objeto cognoscivel; ademais, ao afrontarmos o resultado da "separação" (aí outro parônimo: dissidir, dissídio) entre o sentir e o saber sempre vamos gerar um conflito de interesses ou de opiniões (para a pesquisa etimológica cf., Novísimo diccionario Latino-Português Etymologico, Prosodico, Histórico, Geografico, Mitológico, Biographico etc., organizado L. Quicheratç Fr. dos Santos Saraiva. Rio/Paris: Garnier, 1927).
} 
A educação é um exercício da razoabilidade do conhecer (do lógicamente plausível), por isso proporcional nos seus déficits e na sua suficiência. Ainda assim, todo decidir, seja na educação, seja na vida em geral, produz o sentir de uma insatisfação: uma perspectiva negativa do sentir e do saber. Esta perspectiva negativa do saber e do sentir está numa tensão dialética de dois discursos: um que aponta para a coerência inserta em todas as decisões, outro que nega qualquer coerência. A racionalidade conseqüente, o razoável, está na assertiva de que há razões suficientes para crer que todas as decisões são em parte coerentes e, em parte, incoerentes pendentes dos sujeitos postos em relação.

O sentir, o saber e o decidir são tributários do fazer!

O fazer é sempre um produzir e um provocar: objetivos fundamentais na educação. Todo fazer se revela numa ação transeunte que produz atualidade e provoca transformação, por isso é poíesis e praxis. Poíeses (de $\pi$ oı́́) no sentido grego mais amplo: uma vontade (um conatus, diria Spinoza) de criação, até mesmo de antecipação do devir, um processo de transformação informado pelo trabalho humano e, aí, se metamorfoseia na práxis (de $\pi \rho \alpha \xi_{1} \varsigma, \pi \rho \alpha ́ \gamma \mu \alpha$ ), na produção que (de)compõe e cria, e recria, que interpreta, e reinterpreta, que articula, desarticula e torna a rearticular sem mais certezas prévias senão a constante poíesis: de fazedor, de inventor ou criador de noemas $^{24}$ : sentidos e significações. Enfim, o fazer permite ao ser humano construir a si mesmo e o seu mundo, de forma livre e autônoma, nos âmbitos do cultural, do político, etc.

Desde o articulado acima, afirmamos que todo o agir humano é um movimento constante de educação: do sentir, no saber, e no decidir para fazer. Todo o agir supõe, portanto, o sentir para saber, o saber para decidir e o decidir para fazer. Educar-se, pois, é um modo de estar no mundo: fazendo, decidindo, sabendo e sentindo, num permanente circuito de reação cultural.

\section{A EDUCAÇÃO ESTÁ NO CENTRO DE NOSSO FUTURO: LUGAR APROPRIADO PARA UM APRENDIZADO E CRÍTICA DOS DIREITOS HUMANOS}

"A educação está no centro de nosso futuro." Esta é a primeira afirmação contida na epígrafe que preambula este ensaio. Revela esta assertiva uma "racionalidade proléptica", vale dizer, uma razão de antecipação, pois acolhe no presente, de modo imediato, o porvir. Em seguida, Bassarab explica que o futuro é estruturado pela educação que é dispensada no presente, aqui e agora... Se acima afirmamos que "educar-se é um modo de estar no mundo", o seu processo implica uma tensão entre o aqui e agora do que posso sentir e saber, e o aqui e agora do que posso decidir e fazer.

Uma tensão entre um presente imediato e um presente mediato - ambos prolépticos - cujo resultado está sempre porvir, vale dizer se prolonga no tempo, está, pois, também

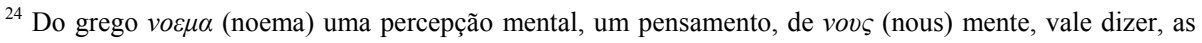
faculdades para perceber e para sentir, para estimar, para determinar. Falamos, portanto, da faculdade humana para superar as faculdades para perceber e para sentir, para estimar, para determinar Falamos, portanto, da faculdade humana de superar o "lugar comum", e postular novos sentidos ou finalidades à própria ação de refletir e de atuar.
} 
no futuro. O aprendizado e a crítica dos direitos humanos podem ser encontrados neste presente que se prolonga...

Os direitos humanos são aqui e agora os resultados do agir de homens e mulheres na luta permanente (o presente que se prolonga...) pela conquista da dignidade do humano: não de uma "dignidade" abstrata, encontradiça em (con)textos soteriológicos, da religião, da moral ou do direito, uma dignidade "pura", "centrada", concessão de instâncias superiores, de normativos pactuados desde uma "posição original" onde os sujeitos estão convenientemente protegidos pelo "véu da ignorância" que se desvela na produção de ideologias de dominação, cuja a racionalidade é apenas a inteligência dos interesses [...] que transformam os homens e mulheres em objetos de programação ou de benefícios planificáveis ${ }^{25}$.

Não! Não é desta noção preconcebida que estamos nos referindo, nos referimos a uma dignidade em permanente construção, "impura", "periférica", que recusa a ficção dos pactos em pró da realidade do dissenso, do pranto, do riso, do encanto e do desencanto, uma dignidade mestiça, que não discrimina que postula o direito à indiferença $(!)^{26}$ pois postular a diferença já é distinguir e separar. Dignidade, portanto, "[...] supone obtener el suficiente poder-espiritual y, sobre todo, materialpara desarrollar esa "estructura de sentimientos" que nos capacite para la indignación y nos revele que, al lado de los dogmas y prejuicios, también existe la voluntad de cambio y transformación de lo real, como com insistência tem proclamado, nosso mestre e irmão de Sevilha, Joaquín Herrera Flores ${ }^{27}$.

Os direitos humanos, nesta perspectiva, revelam-se num processo cultural que reclama uma educação permanente e exige de nós: a capacidade de sentir, a disponibilidade para o saber, o compromisso em decidir e o dever de fazer o necessário para a sua concretização, pois os direitos humanos estão no centro de nosso futuro. Uma educação para os direitos humanos é uma educação que se contextualiza no presente sem olvidar o textual do pretérito, e evita qualquer entronização do futuro: basta-lhe a prolongação do presente.

Uma educação crítica para os direitos humanos aponta tanto para a inteligência como para a vontade. Tem como finalidade nuclear desenvolver uma apurada compreensão humana dos valores que eles encerram e da necessidade que representam suas normas (princípios e regras), positivadas ou não, para a concretização da dignidade de ser, valor maior inscrito na riqueza humana. Contudo, não basta à educação e à crítica em sede de direitos humanos - e mesmo daqueles fundamentais positivados nas legislações estatais - a tão-só racionalidade, pois se pode aceder ao irracional ${ }^{28}$. Exige-se o

${ }^{25}$ Cf. CASTANHEIRA NEVES, A., O Direito hoje e com Que Sentido? O problema actual da autonomia do direito. Lisboa: Instituto Piaget, 2002, p. 45 e 50

${ }^{26}$ Postular o direito à indiferença revela uma adiaforia positiva, não se trata do adiphoron morale de que trata Kant (cf. nota $\mathrm{n}^{\circ} 15$ retro) no sentido de ações julgadas moralmente indiferentes, trata-se sim de $u m$ direito ao reconhecimento do outro como igual, trata-se de um passo do direito à diferença para a diferença de direito que relativiza a identidade cultural ao afirmar a materialidade de igual dignidade para todos os seres humanos.

${ }^{27}$ Cf., HERRERA FLORES, J., El Proceso Cultural. Materiales para la creatividad humana. Sevilla: Aconcagua, 2005, p. 19

${ }^{28}$ Atente-se, na realidade não há o racional e o irracional fora do conhecimento, pois como dizia Pontes de 
concurso da vontade (um otimismo da vontade, diria Gramsci), uma capacidade de escolha fundada no desejo de decidir entre várias alternativas possíveis, por isso, aqui, vontade está muito próxima da definição que lhe atribuiu o empirismo: um impulso, um "fazer sentiente" (a expressão é do grande Xavier Zubiri ${ }^{29}$, ao integrar à vontade os níveis emotivos da pessoa), através do qual o humano se manifesta na realidade objetiva e, assim, conduz a sua atividade mental.

A primeira pergunta, que um programa de educação, no âmbito dos direitos humanos tem de responder corresponde: "Afinal, o que são os Direitos Humanos?". Muitas poderão ser as respostas, segundo a particular concepção ideológica que deles tenha o sujeito que interroga. Contudo uma só resposta é ineliminável: os direitos, quaisquer direitos são, sempre, produtos culturais.

Como produto cultural, o direito é central em qualquer programa de educação. São produtos resultantes de um "conjunto de procesos (normativos, institucionales y sociales) que abren y consolidan espacios de lucha por la dignidad humana" ${ }^{\text {. }}$. O conjunto de processos que abrem e consolidam espaços de lutas pela dignidade humana, diz Joaquín Herrera Flores, se concreta em objetos que revelam valores, normativos e instituições, ademais das práticas sociais que conformam o espaço onde a liberdade e a igualdade sejam possíveis para todos os seres humanos ${ }^{31}$. Este conjunto de processos, assim fundamentado, está aí garantindo "espacios de luchas", pois violar os direitos humanos no es sólo transgredir el derecho, mas, também, e especialmente, impedir la "lucha" para hacer efectivo el derecho; mais ainda, violar este espaço é "descubrir en el análisis del pequeño momento singular el cristal del acontecimiento total" 32 .

Como produtos culturais, os direitos humanos e os direitos fundamentais, acolhidos os primeiros, e inscritos os segundos nas Constituições modernas, respondem a um peculiar sintagma ${ }^{33}$ : dignidade da pessoa humana ${ }^{34}$ e a pretensão de segurança, ou

Miranda, "a irracionalidade já é conhecer, e há caminhos para conhecer-se o irracional como tal: o que não conhecemos é o conteúdo, digamos, do irracional, mas por vezes e provavelmente sempre é o que ocorre com o nosso conhecimento" (O problema fundamental do conhecimento. $2^{\mathrm{a}}$ ed. Rio de Janeiro: Editor Borsoi, 1972 p. 93).

${ }^{29}$ ZUBERI, X., Inteligencia Sentiente - Inteligencia y Realidad, Alianza Editorial, 1984

${ }^{30}$ HERRERA FLORES, J., El vuelo de Anteo. Bilbao: Desclée de Brouwer, 2000, p. 52 e 78

${ }^{31}$ Em outro lugar afirmamos: "para Joaquín Herrera Flores los derechos humanos componen una "constelación" donde los "astros" y sus "satélites" son procesos de matiz variado (normativa, política, cultural, social, económico...), cuya trayectoria orbital se revela en los espacios de lucha por la particular concepción de la dignidad humana. Véase que ese "orbital" es híbrido, por mezclar en el "movimiento" de esos astros: el "reconocimiento" de la ruta, en un itinerario de continua "transferencia de poder", riscando el espacio con la "mediación jurídica" (MOLINARO, C. A., Refutación de la escisión derechos y deberes humanos - por una deontología de los derechos humanos. Tesis doctoral. Sevilla: UPO, 2005, p. XXXV), terminando Herrera Flores por afirmar: "los derechos humanos no son categorías normativas que existen en un mundo ideal que espera ser puesto en práctica por la acción social. Los derechos humanos se van creando y recreando a medida que vamos actuando en el proceso de construcción social de la realidad" (El vuelo de Anteo, p. 27).

${ }^{32}$ BENJAMÍN, W. Paris, Capitale du XIXe Siècle: le Livre des Passages. Paris: Cerf, 1982 p. 12

${ }^{33}$ Utilizamos a expressão sintagma no sentido grego tardio de $\sigma \dot{v} \tau \alpha \gamma \mu \alpha$, do verbo $\sigma v v \tau \alpha ́ \sigma \sigma \omega$, isto é, coisa alinhada com outra, ou um conjunto de expressões lingüísticas em que um termo-representação funciona como unidade.

${ }^{34}$ Em sede de direitos fundamentais, tem insistido Ingo Wolfgang Sarlet - magistrado, professor e distinto amigo com quem muito apreendemos mercê de sua inquestionável capacidade intelectual e afinada sensibilidade 
garantia, atribuída pelo ordenamento jurídico. Este sintagma garantista está sustentado por quatro grandes pilares, sem os quais qualquer garantia é insubsistente, qualquer fundamentação é ineficaz e qualquer processo pedagógico é inútil, que são: o primeiro pilar (1) implica que uma educação para os direitos humanos deve envolver uma atitude ética inovadora, e está obrigada a resgatar: (a) a recuperação do político, já que os direitos humanos não são prévios ou posteriores ao político, sim que neles se dá uma interação contínua entre bens e necessidades, num circuito onde a conquista dos bens necessários para a vida digna está devidamente garantida no normativo jurídico positivado (direitos fundamentais); (b) recuperar o social, pois sem desenvolvimento social não podemos falar de direitos humanos, já que necessária a integração contextual, sem integração contextual, qualquer pretensão de garantia é mera abstração e o valor dignidade uma ficção; (c) recuperar a concepção de ser humano integral, medida de todas as coisas como já afirmou um filósofo grego, pois o ser humano é o "metropoiós" 35 de que fala Aristóteles, o criador de gramáticas e medidas, sem essa perspectiva qualquer garantia é inócua; (d) o agir para a recuperação do entorno, desde a estimulação de uma consciência ecosocial e política, já que a consciência ecosociopolitica está para a segurança ou garantia, assim como o significante está para o significado na formação do signo motivado lingüístico, vale dizer, a consciência ecosociopolítica (significante) e a segurança ou garantia dado pelo jurídico (significado) compõem uma única imagem (até mesmo arbitrária) onde não existe semelhança de forma entre significado e significante, mas ambos exigem-se mutuamente; (e) recuperar uma visão relacional do humano - estabelecer o diálogo intercultural - pois necessitamos abandonar a noção de "construir o outro", própria

para o magistério -, que devemos entender o valor expressado pelo sintagma dignidade da pessoa humana não como um valor absoluto, sim e melhor (!), como "qualidade intrínseca e distintiva reconhecida em cada ser humano que o faz merecedor do mesmo respeito e consideração por parte do Estado e da comunidade, implicando neste sentido, um complexo de direitos e deveres fundamentais que assegurem a pessoa tanto contra todo e qualquer ato de cunho degradante e desumano, como venham a lhe garantir as condições existenciais mínimas para uma vida saudável, além de propiciar e promover sua participação ativa e co-responsável nos destinos da própria existência e da vida em comunhão com os demais seres humanos" (SARLET, I. W., As dimensões da dignidade da pessoa humana: construindo uma compreensão jurídico-constitucional necessária e possivel, in, VV. AA., Ingo Wolfgang Sarlet org.. Dimensões da dignidade - ensaios de Filosofia do Direito e Direito Constitucional. Porto Alegre: Livraria do Advogado, 2005, p. 37; cf. ainda, Dignidade da pessoa humana e direitos fundamentais na Constituição Federal de 1988. $3^{\mathrm{a}}$ ed., rev. e ampl. Porto Alegre: Livraria do Advogado, 2004, p. 59-60, especialmente pp. 124-141). Dignidade como "qualidade intrínseca e distintiva" do ser humano, aqui vale lembrar que qualidade do substantivo latino qualitas, qualitatis, revela o que é próprio, modo de ser,

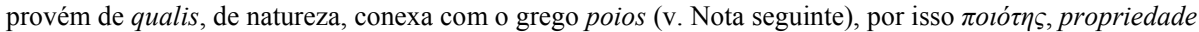
do ser, abrange um leque de conceitos bem examinados por Aristóteles como: hábitos, disposições; capacidades naturais; afeições e sensibilidade; forma (ARISTÓTELES, Met., liv, V, 14, 1020 a 8-12; Cat., 8, 9 a 14, in, Obras Completas, $2^{\mathrm{a}}$ ed. Madrid: Aguilar, 1967, p. 970 e s; p. 243 e s.) todos a revelar como implícitas à dignidade da pessoa humana: determinações disposicionais, sensíveis e mensuráveis, é dizer, capacidade localização espacial e vontade de ocupar esse espaço, capacidade de sentir o real e conduzi-lo profundamente em suas emoções, capacidade de mensurar sua identidade pelo reconhecimento da identidade alheia; em síntese, a dignidade como qualidade intrínseca do ser humano o leva para o reconhecimento, respeito, reciprocidade e responsabilidade para consigo mesmo e para com o outro.

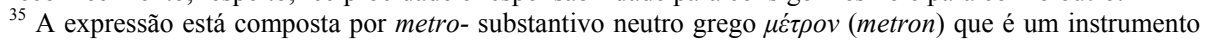

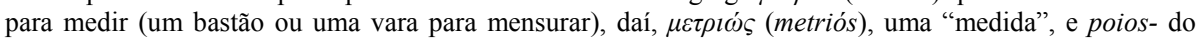

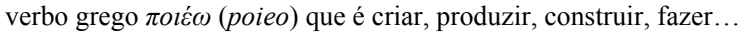


do pensamento ocidental, não há a construção do outro, o que impossibilitaria qualquer dignidade e refutaria qualquer garantia, há, sim, o abrirmo-nos para o outro, solidarizarmo-nos com ele ou, como com propriedade, narra Steiner" ${ }^{36}$, "nos apretamos estrechamente unos juntos a los otros y somos compactamente nosotros mismos"; e, finalmente (f) recuperar as noções de espaço e tempo existenciais, adotando-se concepções que os una a particulares contextos do nosso cotidiano (onde estão incluídas, até mesmo as utopias), pois toda garantia assegura uma periodicidade e uma extensão, atesta uma fidúcia nos recursos com que podemos contar, e uma certeza de pertencimento e respeito ao grupo social em que estamos inseridos.

O segundo pilar (2) está assentado em uma "postura crítica" que saiba conciliar a tensão existente entre o debate que se dá entre as posturas particularistas e as universalistas, pois nem uma, nem outra, desde o ponto de vista prático, são sustentáveis em suas formas extremas: por um lado, os particularistas se apóiam, amiúde, num conceito excessivamente estático e monolítico das relações inter-humanas havidas num cronotopos dado, demonstrando incapacidade de registrar as tensões e as mutações internas de cada comunidade (círculo social); de outro lado, os universalistas se expõem a uma crítica de signo oposto, não alcançando a compreensão das implicações culturais contidas no próprio processo de difusão da linguagem no âmbito dos direitos humanos e dos direitos fundamentais.

O terceiro pilar (3) está centrado em um "compromisso relacional de matriz materialista", um compromisso que é o resultado da assunção do outro desde o seu reconhecimento, como sujeito pleno de direitos e deveres, o que dá origem a uma série de inferências irrefutáveis e necessárias.

Finalmente, o quarto pilar (4) se funda na adoção de uma "visão holista", funcional e sistêmica dos direitos (humanos e fundamentais) enquanto mecanismo de adaptação e corrigenda de adaptação das relações sociais, esta característica é fundamental a qualquer pretensão de segurança e ínsito ao modo consciencial de perceber a dignidade do humano.

\section{UMA EDUCAÇÃO EM DIREITOS HUMANOS, E EM DIREITOS FUNDAMENTAIS, IMPLICA UMA FUNDAMENTAÇÃO FILOSÓFICA E UMA CRÍTICA DESTES MESMOS DIREITOS}

Todo filosofema em sede de direitos humanos, e mesmo em direitos fundamentais, implica num processo educativo onde o homem e a mulher, cada um deles em conjunto ou separadamente, buscam compreender a si mesmos, bem como a realidade com que se confrontam, municiando-se para as atividades de caráter prescritivo ou prático cujos objetivos são as suas ações concretas e os resultados das mesmas, sejam éticos, estéticos, sociais, políticos ou jurídicos.

Filosofar ou Educar guarda o mesmo núcleo duro: o questionamento e a reflexão; ambos utilizam como metodologia - qualquer seja a denominação que queiramos dar - a maiêutica socrática, isto é, desde meditações, ponderações e objeções, apresentar uma multiplicidade de perguntas copulativas induzindo o interlocutor na descoberta

${ }^{36}$ STEINEIR, G., En el castillo de Barba Azul. Barcelona: Gedisa, 1998, p. 156 
de suas próprias verdades, e na apercepção e conceituação geral de um objeto dado.

O filosofar e o educar têm uma estética comum: a condução do olhar. Disciplinar o "ver" é induzir ao descobrimento do perceptível pelos sentidos, e só depois, o percebido pela inteligência. Uma estética que se funda numa metódica heurística, aonde o interlocutor vai adquirindo essa estesia ${ }^{37}$ do olhar, ou uma capacidade sensível que lhe faz descobrir o que se lhe quer in-formar.

\section{O QUE QUEREMOS DIZER QUANDO FALAMOS DE FUNDAMENTAÇÃO FILOSÓFICA E CRÍTICA DOS DIREITOS HUMANOS E DOS DIREITOS FUNDAMENTAIS}

Fundamentar é assentar um conjunto de princípios sobre os quais se podem fundar, ou deduzir um sistema, ou uma concorrência de conhecimentos, intentando lograr, ainda que provisoriamente, um consenso ou, pelo mínimo, contribuir para dissipar dúvidas. Quando falamos - neste ensaio - de fundamentação filosófica dos direitos humanos e dos direitos fundamentais o fazemos numa perspectiva culturalista, desde um sentido e de uma história (ocidental), pois o homem e a mulher são seres históricos, têm consciência de si mesmos e do entorno a que estão submetidos, conhecem, portanto, sua temporalidade na dimensão integral do passado que foi e do futuro que antecipa, permitindo-se, assim, viver o presente com um sentido que expressa reflexão e ação.

Possuir uma consciência histórica, dizia Freire - citando Furter - "consiste en permitir la toma de conciencia de nuestra plena humanidad, como condición y obligación, como situación y proyecto" ${ }^{38}$, como passado, presente e futuro inter-relacionados. Possuir sentido é saber conectar dialeticamente o sentir do outro, singular e coletivo, nos processos históricos, buscando sempre os compreender, como dizia Gramsci, desde um postulado de "superior concepción de la historia, científica y coherentemente elaborada" $"$.

Se o saber é uma indispensável ferramenta para conhecer e transformar a realidade, é através da fundamentação filosófica dos direitos humanos e dos direitos fundamentais - como a entendemos - o que vai sustentar que as relações entre os seres humanos são essencialmente problemáticas e, na maior parte das vezes, contraditórias. Portanto, seu objeto se constitui na tentativa de mediatização dos sujeitos interlocutores, dos sujeitos em interação e deles com o mundo. Uma razoável fundamentação desses direitos é o atrator mais eficaz para a educação em direitos humanos e fundamentais, pois tal fundamentação possibilita o mútuo reconhecimento dos sujeitos cognoscentes, protagonistas em processos culturais de interação, de comunicação entre reflexão e ação, enfim, entre teoria e prática.

Um grande pedagogo catalão, Octavi Fullat, já firmou: "Lo humano se entiende como una contienda indispensable entre lo individual y lo social" ${ }^{\text {, }}$, pois, o animal humano, à semelhança da maioria de outros animais, é gregário por natureza, pensá-lo

\footnotetext{
${ }^{37}$ Do grego aisthesis $(\alpha \imath \eta \eta \sigma ı)$, sensação, ou a percepção dos "sensíveis comuns" - percepção percepcionada.

${ }^{38}$ FREIRE, P., Pedagogía del oprimido. Buenos. Aires: Siglo XXI, 1985, p. 108

${ }^{39}$ GRAMSCI, A., El materialismo histórico y la filosofia de Benedetto Groce. México: Pablos Edit., 1986, p. 146

${ }^{40}$ FULLAT, O., Política de la educación - Politeya y Paideia. Barcelona: Ediciones CEAC, 1994, p. 87
} 
isoladamente resulta um nonsense, todavia, um agrupamento humano sempre será pensado fazendo referencia ao indivíduo ${ }^{41}$. Aliás, Pontes de Miranda afirmava que "o homem é prisioneiro da vida social, como do mundo físico" ${ }^{42}$, pois a sua condição antropológica reúne o individual na condição relacional natureza/cultura mais o social, somando - afirma Fullat - lo irrepetible y lo común, vale dizer, socializando o individual e individualizando o social, expressando-se o mestre catalão, magnificamente, assim: “[...] Lo humano posee una dimensión inefable y secreta, pero ésta ha podido formarse merced a las transacciones del código genético de cada cual con su entorno humano. Lo propio nuestro es Inter homines esse, estar entre otros hombres; de no ser así, jamás se alcanza el status antropológico. Lo social no hace otra cosa que manifestar la necesidad que tenemos, para existir, de ser vistos y escuchados por los demás". 43

A inafastável reunião entre o individual e o social, funda também uma relação política que se desenvolve na dialética entre o público e o privado, resultado, queirase ou não, de séculos de adaptação do humano da sociedade e da maior densidade de um ou outro termo dessa relação. Está na razão direta da maior predominância de um o mais dos processos adaptativos ${ }^{44}$, conformadores das ideologias dominantes no espaço-tempo social ${ }^{45}$. Esta dialética: publico/privado, é responsável, também, pela inauguração da propriedade privada, pois a propriedade privada tem como origem o sujeito humano relacionado com o outro. É o resultado de sua biografia que está constituída pelo seu corpo e por sua vontade. Sua biografia vai ser definida pelo seu tempo de liberdade e pelo seu espaço de responsabilidade; o seu corpo está vinculado ao território ${ }^{46}$ que ocupa, adquirido no espaço e tempo ocupado. Daí para a expansão coletiva deste modelo foi um passo. Do mesmo modo, esta dialética público/privado está presente na constituição da família, vale dizer, um agrupamento humano formado no interior de cada grupo, por uma relação de parentesco de fundo sexual e, no exterior, pelo compromisso com o social, onde o privado se socializa no alter e o público se interioriza no Estado.

Arqué e Demos passam a dialogar. O resultado é o surgimento de Kratos inaugurando o domínio do indivíduo plural sobre o indivíduo singular. Surge deste modo o aparelho repressivo com as variantes modernas do legislativo, executivo e judiciário.

${ }^{41}$ Cf. FULLAT, O., op. cit., loc. cit.

${ }^{42}$ PONTES DE MIRANDA, F. C., Sistema de Ciência Positiva do Direito, vol. III, $2^{\mathrm{a}}$ ed. Rio de Janeiro: Editor Borsoi, 1972, p. 123

${ }^{43}$ FULLAT, O., op. cit., p. 88

${ }^{44}$ Para Pontes de Miranda, sete são os principais processos de adaptação social: Processo Religioso, com os critérios do sacro e não sacro, do divino e do profano; Processo Ético, com os critérios do Moral e do Imoral; Processo Estético, com os critérios do belo e do feio, do estético e do inestético; Processo Gnoseológico, com os critérios do verdadeiro e do não verdadeiro, verdade e erro; Processo Jurídico, com os critérios do justo e do injusto, do legal e do ilegal; Processo Político, com os critérios da ordem e da desordem, organização social e desorganização social; e, Processo Econômico, com os critérios do útil e no inútil (PONTES DE MIRANDA, F. C., Introducção à Sociologia Geral (mantivemos a grafia original). Rio de Janeiro: Pimenta de Mello, 1926, p. 179-234, especialmente o quadro da pág. 235).

${ }^{45}$ Por exemplo, sociedades com forte predomínio do processo religioso tendem a maior estabilidade, nada obstante, também com maior dogmatismo dos seus preceitos; sociedades onde a predominância está no processo econômico, revelam-se mais acumulativas, não necessariamente mais desenvolvidas, e assim por diante.

${ }^{46}$ Aqui entendemos território como a apropriação de qualquer bem, tangível ou intangível. 
Especializam-se as relações, e o tráfico social passa a produzir necessidades que vão ser supridas pelas relações de produção e consumo, entendidas de modo amplo. Essas necessidades são, em princípio, manifestadas através de discursos racionais e, também, irracionais, isto é, as primeiras, desde critérios de decisão que buscam conformar todos a um acordo e, as segundas, negando qualquer disposição ao acordo. A solução foi à mediação de um discurso de maioria hegemônica, à disposição de muitos ao acordo, mas não de todos - aí está à primeira perversidade da dialética público/privado: a exclusão ou inclusão dos interlocutores pelo critério da racionalidade ou irracionalidade de suas posições; aí também se encontra a maior violação dos direitos humanos: o impedir-se a luta pelos mesmos, através critério da razão que exclui. A autonomia vai ser balizada através desses critérios. Uma pública, com a derivação de funções sistêmicas que lhe são próprias, inaugurando razões constitutivas e regulativas, prevalecendo o coletivo (embora o coletivo não suponha universalismo de convergência ${ }^{47}$ ); outra privada $^{48}$, que inaugura o mercado e todas as relações daí decorrentes ${ }^{49}$.

Divisão política e social (público e privado, com as fragmentações correspondentes), propriedade privada, família (entendida em sentido amplo e até metafórico), necessidades e relações de produção e consumo de bens, são as chaves para a fundamentação dos direitos humanos e dos direitos fundamentais. Os primeiros, com forte conteúdo emancipador e, os segundos, com forte conteúdo regulador. Os primeiros vinculados às lutas para a conquista dos bens reclamados pelas necessidades existenciais, os segundos dedicados à garantia dessas conquistas. Fundamentar ambos é refletir sobre a história, sentir sua presença indelével no presente, decidir sobre o alcance de seus ensinamentos e finalmente fazer, no presente que se prolonga a história, velando para que um dogmatismo não se substitua por outro, como finaliza Bassarab, na epígrafe que preambula este ensaio.

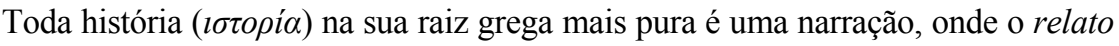
expõe os fatos, individualmente ou a totalidade deles, esse substantivo grego está

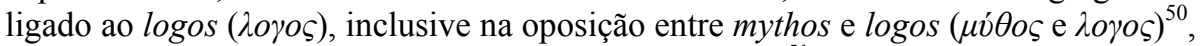
sendo o logos um relato racional, analítico e verdadeiro 51 , contudo este "verdadeiro"

\footnotetext{
${ }^{47}$ Entendemos que toda universalidade é uma totalidade nematológica (do grego $v \varepsilon \mu \alpha-$ nema $=$ fios, filamentos) que incorpora os denominados saberes nematológicos, constituídos por relações filamentares que albergam posturas presuntivamente comuns a todos os componentes de determinada classe ou grupo, sejam de natureza ideológica ou mitológica ou filosófico-mundana; essas totalidades dão lugar aos universalismos de toda espécie; ocorre que esses universalismos não são necessariamente de convergência, isto é, não resultaram da "livre concorrência" de todos ao ponto comum, pois processos de dominação teológica e política sempre se encontram neles subjacentes.

${ }^{48}$ Karl Larenz já afirmava que a autonomia privada se constituía num dos princípios fundantes do Direito Privado (Cf. Derecho Civil: Parte General, Trad. de M. Izquierdo e Macías-Picavea. Madri: Editorial Revista de Derecho Privado, 1978, p. 55).

${ }^{49}$ Cf. FULLAT, O., op. cit., p. 88 e s., 95 e s.

${ }^{50}$ Sendo o mito uma fabulação, ou como diz Cebes a Sócrates no diálogo platônico Fedon: [...] el poeta, si es que se propone a ser poeta, deberá tratar en sus poemas de mitos y no razonamientos... (PLATÃO, Fedon, o del Alma, 61 b, 76 b, in, Obras completas. $2^{\mathrm{a}}$ ed. Madrid: Aguilar, 1969, p. 613 e 624-5

${ }^{51}$ Também é Platão que ensina que o verdadeiro conhecimento (epistéme) está na capacidade de fazer um relato (logos) daquilo que se sabe (in, Teeteto, 206 c - 210 b, especialmente, 208 c; op. cit., p. 938-940).
} 
é um hóros ('ỏ $\rho \sigma o \varsigma)^{52}$ um limite, daí horismo, como a ação de demarcar limites, fronteiras no estudo do sentido e da formação dos termos ou dos relatos da ciência, portanto, a história está nesta fronteira, no espaço interstício do mythos e do logos, no passado onde pode ser interpretada como tradição, assim como no presente que pensa e interroga o passado, numa visão de totalidade da criação humana. Toda a história pode ser circunstanciada a uma unicidade, onde o fato histórico é único e não repetível, quase sempre correlativa, pois esse fato está em constelação com outros relatos e dotada de significado demonstrado pelas conseqüências fatuais decorrentes ${ }^{53}$.

A história dos direitos humanos é também uma narração. Seu relato está bem emoldurado na história mundanal do ser humano. É um relato que medeia o mythos e o logos (até mesmo aquele logos que falava Heráclito, que é medida, cálculo e proporção do que flui do conjunto harmônico de leis, da regularidade e das conexões existentes no $\operatorname{cosmos}^{54}$ ), ora como fábula, ora como verdade, ou como verdade-fábula, isto é como fidelidade a uma representação real ou imaginária, mas sempre intencionalmente evocada à consciência e mais ou menos fiel a um objeto qualquer, ou a um acontecimento anteriormente percebido. É nessa representação vedadeiramente-fabulosa que se desenvolve a fascinante história dos direitos humanos. Os dois adjetivos: fabuloso e fascinante são utilizados propositadamente (ambos têm um conteúdo pedagógico indiscutível), pois o que é fabuloso tem o caráter admirável, e o que é fascinante (nos enfeitiça, o fascino dos latinos) exerce em nós uma forte atração, ambos nos encantam e ambos nos ensinam. Assim, o mesmo se dá com a história dos direitos humanos. Períodos de encantamento e também de desencanto quando infiel a representação deles. Com os direitos fundamentais, o mesmo se dá - estão na história constitucional de um Estado, com os mesmos componentes. Contudo, se os direitos humanos, como processos culturais abertos e emancipadores, estão dirigidos aos seres humanos, independentemente dos limites geopolíticos, os fundamentais, como processos culturais cerrados e reguladores, se inserem nestes limites, buscando garantir neste espaço, as conquistas dos primeiros, até mesmo acolhendo-os via incorporação de normas de superdireito (vale dizer, internacionalizando por dentro o sistema jurídico nacional), ambos com a finalidade essencial de afirmar e promover a dignidade humana.

\section{CONSIDERAÇÕES FINAIS}

Se educação é a resposta. Qual era a pergunta?

A pergunta é uma só, ampla e complexa:

Como podemos coadjuvar para a formação de sujeitos críticos, efetivamente

52 Hóros, no grego é limite ou fronteira, mas, também, definição, ou sentido de uma palavra (cf. Diccionario Manual Griego - Griego Clásico - Español., $18^{\mathrm{a}}$ ed. Barcelona: Vox, 2000, p. 434)

${ }^{53}$ Cf., ABBAGnANO, N., Dicionário de Filosofia. 4. ${ }^{a}$ ed., verbete História. São Paulo: Martins Fontes, 2000, p. 502-507.

${ }^{54}$ Dizia Heráclito: “Os homens deviam tentar compreender a coerência subjacente das coisas: ela está expressa no Logos, fórmula ou elemento de ordenação comum a todas as coisas" (Cf., Kirk, G. S., Raven, J. E. e Schofield, M., Os Filósofos Pré-Socráticos - História Crítica com Seleção de Textos, $4^{\mathrm{a}}$ ed. Lisboa: Fundação Calouste Gulbenkian, 1994, p. 192-193). 
comprometidos com a dignidade do humano, capazes de fazer valer seus próprios direitos e responsabilidades, bem como os dos outros, mediante propostas e atitudes que contribuam para a luta constante no sentido de erradicar as injustiças que se incrustam na desigual repartição dos bens frente às necessidades que afrontam qualquer noção de dignidade da pessoa humana?

A resposta a esta pergunta só poderia ser enxuta: Educação. Educação em direitos humanos e em direitos fundamentais, como parte integrante e indissociável dos processos de democratização das sociedades.

Uma democratização não só política, mas, também e, especialmente, econômica e cultural. Uma democratização que tenha como núcleo duro o reconhecimento da dignidade da pessoa humana como aquela a que nos referimos nas páginas retro: um conceito mestiço de dignidade que ingressa e transita na sociedade, que confronta igualdade e desigualdade. Duas expressões sempre presentes no discurso dos direitos humanos e fundamentais, a primeira delas, ainda que formada do radical latino cequs,

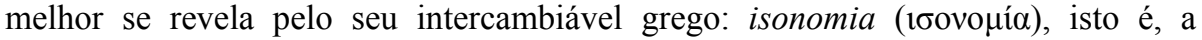
igualdade ante a norma. Neste sentido, toda igualdade formal, relativamente ao normativo, implica na igualdade de direitos. O problema surge quando pensamos na materialidade, vale dizer, quando não basta à igualdade ante a norma, ou quando a igualdade de direitos não é eqüitativa na accountability ${ }^{55}$ sócio-estatal. A segunda - a desigualdade - é sempre ausência de proporção na informação, justificação e punição da assimetria ao compartir as responsabilidades.

Uma democratização que permita o resgate da memória histórica e da intersubjetividade. Por último, uma educação em direitos humanos implica numa participação efetiva nos processos de emancipação dos seres humanos, isto é, uma educação em direitos humanos não pode estar divorciada de uma educação em direitos fundamentais, pois se implicam para capacitar um conhecimento básico do conjunto de disposições não só normativas (princípios e regras) constitucionalfundamentais, mas, de modo especial, de uma linguagem relacional destes direitos de modo a valer-se destes saberes como instrumento para exigir a vigência das garantias e responsabilidades, ademais da vigilância constante de sua eficácia e efetividade.

Educação dos saberes, educação dos sentimentos, educação nas decisões e educação na ação capacitam-nos a enfrentar as gravíssimas questões que atormentam nossas instáveis e frágeis democracias: a pobreza dos meios e dos resultados sejam estes éticos, políticos, econômicos ou jurídicos; a injustiça social formal ou institucional, e a das máfias por vezes nelas embutidas; a violência pública e

\footnotetext{
55 Cf. SMUlOvitz, Catalina e PERUZZOTTI, Enrique. Societal Accountability in Latin America. Journal of Democracy, 2000/11(4): 147-158. O princípio de accountability societal funda-se na incisiva ação dos mais distintos consórcios de cidadãos, movimentos sociais, e mesmo o conjunto da mídia comprometida com a ação social com o objetivo de apontar erros e disfunções governativas, ademais de atrair a atenção para novas questões na formatação da agenda pública e influenciar na tomada de decisões políticas cuja implantação seja necessária. Enfim, uma forma de avaliação e controle de políticas e procedimentos pela sociedade civil.
} 
privada, com a impunidade e a corrupção nos âmbitos do público e do privado; a discriminação de qualquer tipo, e a intolerância que nega qualquer possibilidade de um discurso intercultural.

Uma educação em direitos humanos e em direitos fundamentais implica em dar voz aos cidadãos. Dar-lhes voz, mas dar-lhes também visibilidade legal, e.g., os movimentos sociais dos excluídos, os "sem de toda espécie...", a defesa da ecologia, o sexismo, a questão de gênero, a integração étnica, as dos portadores de necessidades especiais, a real e efetiva defesa do consumidor, os mercados alternativos formalizados ou informais, o antimilitarismo e outras formas de objeção de consciência, a necessidade crescente de solidariedade internacional e tantas outras; todas essas vozes dificilmente podem estar albergadas desde uma só perspectiva ideológica. Portanto, para superar a crise em que nos encontramos, e para satisfazer questionamento racional de convicções, crenças e dogmas - ainda que legitimadas pela tradição ou impostas por autoridades políticas ou religiosas - necessitamos estabelecer uma educação em direitos humanos com uma especial pauta de ação: uma pedagogia e uma metodologia da práxis social que busque compromissos setoriais entre as mais plurais concepções de justiça social que defendam as minorias cada vez mais conscientes e predispostas à participação e a transformação político-social.

Logo, necessitamos desvelar pela educação, o contrapor da política ao Estado, o fortalecimento da esfera público/política através de: (a) uma formação política cidadã no sentido de uma verdadeira cultura republicana; (b) o aprofundamento político das liberdades científicas e culturais; (c) a imperativa exigência de "responsabilidade social" dos políticos e dos demais condutores e agentes públicos, bem como a democratização interna dos partidos políticos; e, (d) o empoderamento efetivo do cidadão sobre o aparato do Estado, exercendo o controle sobre a administração, postulando pela extensão da participação social-democrática e legislativa, em assembléias, audiências públicas, pelos plebiscitos e referendos, e pela Internet.

Certamente, se combinarmos, pedagogicamente, o ideal dos direitos e sua efetividade ao pluralismo e as idéias de liberdade e igualdade para todos, isto é, a uma nova concepção ético/política de cidadania, poderemos restaurar a dignidade do político e da política, e proporcionar o veículo da construção de uma hegemonia democrática radical, num Estado Social e Democrático de Direito inclusivo. Críticas e crises paidéticas, também, certamente continuarão a existir, porém seus efeitos, só serão visíveis com novas necessidades que se irão formando em nosso percurso existencial, pois a educação é um processo permanente de construção de identidade e um dever do Estado de Direito que reconhece os direitos humanos e os fundamentais, para que possa ser efetiva a nossa dignidade de pessoas, ademais de podermos gozar com ela, especialmente, uma parcela da cidadania que se encontra em situações objetivamente difíceis por razões econômicas, de saúde, sociais ou culturais. Como itinerário, a educação é um caminho que se faz ao andar, e ao andar especializa e aperfeiçoa o ser humano. Dir-nos-ia o grande poeta espanhol Antonio Machado: 
Caminante, son tus huellas ${ }^{(56)}$

el camino, y nada más;

caminante, no hay camino,

se hace camino al andar.

Al andar se hace camino,

y al volver la vista atrás

se ve la senda que nunca

se ha de volver a pisar.

Caminante, no hay caminos,

sino estelas ${ }^{(57)}$ en la mar ${ }^{58}$.

\section{REFERÊNCIAS BIBLIOGRÁFICAS}

ABBAGnANO, N. Dicionário de Filosofia. $4^{\mathrm{a}}$ ed., verbete História. São Paulo: Martins Fontes, 2000.

ARISTÓTELES. Met., liv, V, 14, 1020 a 8-12; Cat., 8, 9 a 14, in, Obras Completas, $2^{\mathrm{a}}$ ed. Madrid: Aguilar, 1967.

. Del Alma, 425b, in, Obras Completas. $2^{\text {a }}$ ed. Madrid: Aguilar, 1967.

BASSARAB NICOLESCU. Manifesto da Transdisciplinaridade. São Paulo: Triom, 1999.

BENJAMÍN, W. Paris, Capitale du XIXe Siècle: le Livre des Passages. Paris: Cerf, 1982.

CANDEL, M. Prólogo, in, Searle, J., Libertad y neurobiología, Barcelona: Paidós, 2005.

CASTANHEIRA NEVES, A. O Direito hoje e com que Sentido? O problema actual da autonomia do direito. Lisboa: Instituto Piaget, 2002, p. 45 e 50.

FOUCAUlT, M. As palavras e as coisas. Trad. De A. R. Rosa. Lisboa: Martins Fontes/Portugália Ed., s/d., possivelmente de 1967, p. 450-451 (ed. francesa Ga1imard, 1966).

FREIRE, P. Pedagogía del oprimido. Buenos. Aires: Siglo XXI, 1985. XXI, 1979.

¿Extensión o Comunicación? La concientización en el medio rural. México: Siglo

FULlAT, O. Política de la educación - Politeya y Paideia. Barcelona: Ediciones CEAC, 1994.

GRAMSCI, A. El materialismo histórico y la filosofía de Benedetto Groce. México: Pablos Edit., 1986.

HERRERA FLORES, J. El Proceso Cultural. Materiales para la creatividad humana. Sevilla: Aconcagua, 2005.

. El vuelo de Anteo. Bilbao: Desclée de Brouwer, 2000.

JASPERS, K. Philosophie (1932), trad. Filosofia. Madrid: Revista de Occidente, 1959.

KANT, I. La religión - dans le limites de la simple raison. Trad. J. Gibelin, 10 a ed. Paris: Librairie Philosophique J. Vrin, 1952, p. 41R.

${ }^{56}$ Pegada, vestígio que o pé do homem ou do animal deixa no solo por onde passou, mas, também, tudo aquilo que sugere a possível existência de alguma coisa.

${ }^{57}$ Estela: rastro espumoso, deixado pelos barcos na água quando navegam. Contudo, estela é também "trilha", estrela, e ainda, "bloco de pedra erigido como monumento".

${ }^{58}$ Machado, A. Proverbios y Cantares (CXXXVI), in Poesias Completas. Barcelona: Espasa Calpe, 2001, p. $239-240$ 
PANNIKAR, R. Myth, Faith and Hermeneutics. New York: Paulist Press, 1979.

Cross Cultural Studies: The need for a new science of interpretation, Interculture, v, VII, n. 3-5, Cahier 50, 1975.

KIRK, G. S., RAVEN, J. E. e SCHOFIELD, M. Os Filósofos Pré-Socráticos - História Crítica com Seleção de Textos, 4. ${ }^{\text {a }}$ ed. Lisboa: Fundação Calouste Gulbenkian, 1994.

LARENZ, K. Derecho Civil: Parte General, Trad. de M. Izquierdo e Macías-Picavea. Madri: Editorial Revista de Derecho Privado, 1978.

MACHADO, A. Proverbios y Cantares (CXXXVI), in, Poesias Completas. Barcelona: Espasa Calpe, 2001.

MARVIN, H. Introducción a la antropología general. Madrid: Alianza editorial, 1984.

MERLEAU-PONTY, M. Le visible et l'invisible. Paris: Gallimard, 1964.

MOLINARO, C. A. Refutación de la escisión derechos y deberes humanos - por una deontología de los derechos humanos. Sevilla: UPO, 2005.

NIETZCHE F. Asi habló Zaratustra. Un libro para todos y para nadie. Madrid: Alianza, 1972.

PLATÃO. Fedon, o del Alma, 61 b, 76 b, in, Obras completas. $2^{\mathrm{a}}$ ed. Madrid: Aguilar, 1969.

PONTES DE MIRANDA, F. C. Sistema de Ciência Positiva do Direito, vol. III, $2^{\mathrm{a}}$ ed. Rio de Janeiro: Editor Borsoi, 1972.

O problema fundamental do conhecimento. $2^{\text {a }}$ ed. Rio de Janeiro: Editor Borsoi, 1972.

. Introducção à Sociologia Geral, Rio de Janeiro: Pimenta de Mello, 1926

SARLET, I. W. As dimensões da dignidade da pessoa humana: construindo uma compreensão jurídico-constitucional necessária e possivel, in VV. AA., Ingo Wolfgang Sarlet org.. Dimensões da dignidade - ensaios de Filosofia do Direito e Direito Constitucional. Porto Alegre: Livraria do Advogado, 2005.

Dignidade da pessoa humana e direitos fundamentais na Constituição Federal de 1988. $3^{\text {a }}$ ed., rev. e ampl. Porto Alegre: Livraria do Advogado, 2004.

SCHELling, F. W. J. Philosophies de l'Université, Paris: Payot, 1979.

SEARLE, J., La construcción de la realidad social. Barcelona: Paidós, 1997.

SMULOVITZ, Catalina; PERUZZOTTI, Enrique. Societal Accountability in Latin America. Journal of Democracy, 2000/11(4): 147-158.

SOTO RIVERA, R. Kairo-teo-ontología en algunos pensadores grecorromanos, in, Konvergencias, Bayamón [Puerto Rico]: Impresos GLAEL, año II - Edición Diciembre 2003/Enero 2004.

STEINER, G. En el castillo de Barba Azul. Barcelona: Gedisa, 1998.

WAGENSBERG, G. Si la naturaleza es la respuesta, ¿cuál era la pregunta? Y otros quinientos pensamientos sobre la incertidumbre. Barcelona: Tusquets Editores, 2001.

ZUBERI, X. Inteligencia Sentiente - Inteligencia y Realidad, Alianza Editorial, 1984.

DICIONÁRIOS:

Diccionario Manual Griego - Griego Clásico - Español., $18^{\mathrm{a}}$ ed. Barcelona: Vox, 2000.

Novísimo diccionario Latino-Português Etymologico, Prosodico, Histórico, Geografico, Mitológico, Biographico etc., organizado L. Quicheratç Fr. dos Santos Saraiva. Rio/Paris: Garnier, 1927. 